\title{
Plantain and Banana Research at the International Institute of Tropical Agriculture
}

The International Institute of Tropical Agriculture (IITA), established in Ibadan, Nigeria, as an international institute for agricultural research and training, celebrated its 25th anniversary in 1992. It became the first African link in a worldwide network of international agricultural research centers funded by the Consultative Group on International Agricultural Research (CGIAR), an association of more than 40 public and private donors, including government agencies, international organizations, and private foundations. IITA's mission is "to improve the nutritional status and well-being of low-income people in the humid and subhumid zones of sub-Saharan Africa by carrying out research and related activities for increasing agricultural production in a sustainable manner, in cooperation with national and international systems and institutions."

IITA conducts research and training activities on a 1000-ha farm at Ibadan and at stations in sub-Saharan Africa. Its activities are linked with regional and national programs throughout Africa. To enhance the practical relevance

Received for publication 1 Oct. 1992. Accepted for publication 11 Nov. 1992. We acknowledge R. Swennen and G.F. Wilson, former International Institute of Tropical Agriculture (IITA) plantain scientists; other colleagues at IITA; and E. De Langhe and G. Sery, International Network for the Improvement of Banana and Plantain, for their close involvement. We thank P.D. Austin for support in farm management research, physical plant and laboratory operations, and M. Winslow for useful comments on the manuscript. Plantain and banana research at IITA has benefited from grants by several donors, particularly the Belgian Administration for Development Cooperation. The cost of publishing this paper was defrayed in part by the payment of page charges. Under postal regulations, this paper therefore must be hereby marked advertisement solely to indicate this fact.

'Leader/Tissue Culturist, Plantain and Banana Improvement Program. To whom reprint requests should be addressed at IITA, c/o L.W. Lambourn and Co., 26 Ding wall Rd., Croydon CR9 3EE, England.

${ }^{2}$ Breeder/Geneticist, Plantain and Banana Improvement Program.

${ }^{2}$ Pathologist, Plant Health Management Division. ${ }^{4}$ Entomologist, Plant Health Management Division. ${ }^{5}$ Postharvest Specialist, Plantain and Banana Improvement Program.

${ }^{6}$ Nematologist, Plant Health Management Division.

Front cover: Black-sigatoka-resistant tetraploid hybrid TMPx 2796-5 obtained by crossing the susceptible triploid 'Bobby Tannap' plantain with the highly resistant cultivated diploid 'Pisang lilin' banana. (left inset) Symptoms of black sigatoka leaf spot disease on plantain. (right inset) Plantain plantlets produced by in vitro shoot-tip culture. of its research, IITA has begun to decentralize its research into the various agroecological zones where its mandated crops-maize (Zea mays L.), cowpea [Vigna unguiculata (L.) Walp. ssp. unguiculata], soybean [Glycine max (L.) Merr.], plantain and banana (Muss spp. L.), cassava (Manihot esculenta Crantz), and yam (Dioscorea alata L.) - are grown. IITA's Onne station lies in the high-rainfall coastal zone of West Africa near Port Harcourt, in southeastern Nigeria. Established in 1976, it is the oldest station and covers 100 ha. A main activity at Onne is interdisciplinary research on plantain and banana. A new station is being established at Namulonge, Uganda, in the East African highlands, where banana research is also developing.

\section{Plantain and banana in Africa}

Plantain and banana are important food crops in the humid forest and mid-altitudes of sub-Saharan Africa. They provide more than $25 \%$ of the carbohydrates for $\approx 70$ million people in the region. In addition to being a mainstay for rural and urban consumers, plantain and banana provide an important source of revenue for smallholders, who mainly produce them in compound or home gardens. The gross value of annual production exceeds that of several other main food crops, such as maize, rice (Oryza sativa L.), cassava, and sweetpotato [Ipomoea batatas (L.) Lam.].

Most cultivated Musa are triploids $(2 \mathrm{n}=3 \mathrm{x}$ =33). Almost completely sterile, they develop fruit by parthenocarpy. The most important cultivars vary in their genomic constitution: dessert banana (AAA), East African highland banana (AAA), plantain ( $\mathrm{AAB}$ ), and cooking banana (ABB). The genome of the cultivated types is derived from the diploid wild species $M$. acuminata Colla. (A genome) and $M$. balbisiana Colla. (B genome).

Although Southeast Asia is considered to be the center of origin of Musa spp. (Simmonds, 1966), a remarkable diversity of plantains and bananas exists in sub-Saharan Africa (Swennen and Vuylsteke, 1991). Each of the different types is grown in a distinct subregion. The $\mathrm{AAB}$ plantains are predominant in the humid lowlands of West and Central Africa, while AAA cooking and beer bananas prevail in the East African highlands. The former region harbors the world's greatest variability of plantains and, thus, is considered a secondary center of plantain diversification. A similar situation is found for the specific East African bananas of the Musa AAA group. Simmonds (1966) has referred to upland East Africa as a secondary center of origin and diversity of the AAA bananas. The wide and unique morphological variation manifested by the African plantains and bananas reflects along history of cultivation of the crop in the region (De Langhe, 1969).

\section{Production constraints}

Sub-Saharan Africa produces $\approx 35 \%$ of the world's 68 million tons of bananas and plantains. However, production is threatened by pest and disease pressure, which have been increasing during the past 15 years. Also, rising population pressure on the land has led to shortened fallow periods and, consequently, declining soil fertility. These trends underlie the urgency of IITA's work in this area, particularly that aimed at developing appropriate and ecologically sustainable technology for resource, crop, and pest management in Muss farming systems.

Black sigatoka leaf spot disease, caused by the fungus Mycosphaerella fijiensis Morelet, is generally considered to be the most serious constraint to plantain and banana production in sub-Saharan Africa. The disease was accidentally introduced to this continent about two decades ago and spread rapidly, first in Central and West Africa, and later in East Africa. The pathogen causes severe leaf necrosis, reducing yields by $30 \%$ to $50 \%$. All plantain cultivars, as well as some of the most widely grown banana cultivars of East Africa, are susceptible. Though fungicides will control the disease, they are too expensive for the smallholders who grow most of the crop and are hazardous. The only suitable control strategy for these farmers-one that IITA is pursuing activelyis to provide them with high-yielding, resistant cultivars. Other major diseases, mainly in East Africa, are fusarium wilt and the banana bunchy-top virus.

The banana weevil (Cosmopolites sordidus Germar) is an important insect pest of plantain and banana in Africa. Its larvae bore tunnels in the corm, causing the plant to weaken and lodge. Both plantains and the East African highland bananas are susceptible to the insect. A complex of plant parasitic nematodes [e.g., Radopholus similis (Cobb) Thorne, Pratylenchus spp. Filipjev, Helicotylenchus multicinctus (Cobb)] also creates serious root damage. Weevils and nematodes together interfere with nutrient uptake and transport, resulting in slow growth and reduced fruit filling. In severe cases, the plant lodges. As with black sigatoka disease, chemical control of these pests is undesirable. Banana weevils and nematodes become increasingly severe as a stand ages.

Another formidable obstacle to increasing plantain cultivation is the rapid yield decline that occurs after 1 or 2 years when the crop is grown in open field plantations. In contrast, plantations of dessert banana remain productive for many years, as does plantain within home or village compound gardens, where it benefits from regular applications of organic matter in the form of household refuse. The causes of yield decline are complex. In addition to damage caused by the banana weevil

(continued on p. 970) 
and nematodes, the plants lodge easily under field conditions as a result of poor root development, slow ratooning, and "high mat" (a tendency of the plant base to grow out of the soil). These problems probably can be ameliorated through plant breeding. In East Africa, declining yields (referred to as "banana decline," or "small bunch syndrome" in Uganda) undoubtedly are related to reduced soil fertility and mineral deficiencies in the poorer soils. Yield decline under plantation conditions can be arrested somewhat through mulching.

Postharvest losses of plantain area serious deterrent to expanded production in some African countries. Oversupply during the major production season is the primary cause, but losses can also be attributed to inadequate methods of fruit harvest, transport, and storage.

\section{Musa improvement research: Global perspective}

Banana research was initiated in the early 1900s with the advent of international trade in dessert bananas. Banana breeding started in Trinidad (1922) and Jamaica (1924) (Simmonds, 1966). Currently, the most important breeding program in tropical America is that of the Fundación Hondureña de Investigación Agricola (FHIA, Honduras), which initially was established by the United Fruit Co. in the late 1950 s. These programs primarily were directed toward the needs of the export trades. However, despite more than 70 years of breeding efforts, no manually bred hybrids have been developed; all commercial cultivars are selections from the naturally occurring germplasm. Research also is conducted in Asia and the Pacific, especially in India, the Philippines, Taiwan, and Australia.

In Africa, the Belgians initiated a breeding scheme (De Langhe, 1969), which ceased in 1960 with Zaire's independence. Several national program in Africa have begun plantain and banana research. The Institut de Recherche Agronomique et Zootechnique (IRAZ), located in Burundi, has developed into a regional center addressing the problems of banana production in the East African highlands. French researchers of the Institut de Recherches sur les Fruits et Agrumes (IRFA) also started a large program in several countries before 1970. A recent development of global relevance was the creation in 1984 of the International Network for the Improvement of Banana and Plantain (INIBAP), which joined the CGIAR system in 1991.

\section{Musa research at IITA}

IITA has an international mandate to improve plantains and bananas. Early work at the Onne station focused on collecting plantain germplasm and on agronomic work. IITA's field gene bank currently holds 113 different cultivars of plantain (Musa spp., AAB group) collected from Nigeria, Ghana, Côte d'Ivoire, Cameroon, Congo, Gabon, Burundi, and the Philippines. In addition to the plantain collec- tion, another 300 accessions of Muss, ranging from wild species to the most common export banana cultivars, are maintained at the IITA gene bank at Onne. These genetic resources are held as a breeding resource as well as in trust for the world community and are freely available in accordance with the CGIAR policy on plant genetic resources. Many of the Musa accessions were introduced as in vitro cultures with the concurrence of INIBAP and the Nigerian Plant Quarantine Service (Vuylsteke et al., 1990). The larger part of the field gene bank also is duplicated in vitro using standard shoot-tip culture methodology (Vuylsteke, 1989).

In agronomy, intercropping, mulching, and propagation were investigated, which resulted in a manual on plantain cultivation aimed at national agricultural programs and farmers (Swennen, 1990).

In response to increasing pest and disease pressure on the crop, IITA decided in 1987 to include plantain and banana among the crops for which it conducts genetic improvement, and by 1991 the institute had created a separate program for this purpose. Hence, research focus shifted from agronomy and taxonomy to breeding and crop protection. Nevertheless, the earlier efforts incollecting Musa germplasm and in tissue culture and crop management provided a sound basis for the breeding program. Black sigatoka disease, banana weevil, nematodes, and yield decline are critical issues being addressed through five interdisciplinary projects.

Breeding plantain and banana for durable host-plant resistance to sigatoka diseases. The genetic improvement program at the Onne station incorporates host-plant resistance to sigatoka in plantains and bananas. Resistance breeding is generally considered as the most appropriate strategy to control sigatoka leaf spot. The breeding endeavor advanced more rapidly than anticipated, particularly in view of the commonly accepted intractability of the crop to conventional breeding approaches at the triploid level. About 250 hybrid progenies have been planted in selection fields within 4 years of breeding work. This achievement is largely due to two important prerequisites. First, many female-fertile triploid plantain clones were identified in the field gene bank. Currently, 37 cultivars are capable of producing true seed through hand-pollination, the highest number of seed-fertile plantains reported so far. Second, seed production rates of plantains at the Onne station seem to be higher than for other locations where banana breeding has been undertaken; up to 200 seeds may be extracted from a single triploid plantain bunch when pollinated with a wild diploid banana (Swemen and Vuylsteke, 1993).

Initially, the breeding approach involved producing tetraploid progenies via $3 \mathrm{x} \times 2 \mathrm{x}$ crosses, in which the triploid female plantains produced $2 \mathrm{n}(=3 \mathrm{x})$ eggs. This strategy currently is being extended to include secondary triploid production via further tetraploid $\mathrm{x}$ diploid hybrid crosses. Diploid plantain-banana hybrids have also been recovered from the initial $3 \mathrm{x} \times 2 \mathrm{x}$ crosses. These diploids prove to be very advantageous to plantain breeding, because they provide opportunity for germplasm enhancement at the $2 \mathrm{x}$ level and simplify genetic analyses due to disomic inheritance. As an example of the latter, a genetic model of black sigatoka resistance in plantain was proposed recently (Ortiz and Vuylsteke, 1992).

Thus far, 20 tetraploid hybrids have been selected that combine moderate resistance to black sigatoka, high yields, large fruit, and improved ratooning. In preliminary tests, yields of some of the best-performing hybrids were twice that of the triploid plantain parent (33 and $16 \mathrm{t} \cdot \mathrm{ha}^{-1}$, respectively). To evaluate resistance and yield stability, selected hybrids currently are undergoing multilocational evaluation trials in Nigeria, Cameroon, and Ghana in collaboration with national agncultural programs.

In addition to black sigatoka resistance, future breeding objectives will probably include weevil and nematode resistance, higher yield, improved perennial behavior through better ratooning and shorter plant stature (including dwarfism), and improved postharvest quality.

The current focus of the breeding program is on plantain improvement for the humid forest zone of West and Central Africa. During the next few years, cooking banana improvement for the mid-altitude ecology of East Africa will receive increased emphasis in view of HTA's (sub-Saharan) Africa-wide mandate.

Musa germplasm enhancement using in vitro culture techniques and biotechnology. Efforts to propagate, conserve, and breed cultivated Muss are fraught with many obstacles (low reproductive fertility, slow vegetative propagation, and long growth cycle) specific to the biology of this crop. Hence, plant tissue culture and molecular genetic techniques are being used increasingly as techniques for handling and improving Musa germplasm.

At IITA, shoot-tip culture routinely is used for propagating, exchanging, and conserving Musa germplasm (Vuylsteke, 1989). For example, micropropagation has been pivotal in rapidly supplying large numbers of plants of female and male parents for crossing blocks and of promising new hybrids for evaluation trials. Also, more than 300 new Musa accessions have been introduced as shoot-tip cultures during the past 7 years. Somaclonal variation in plantains derived from shoot-tip culture has been described in detail (Vuylsteke et al., 1991). Embryo culture and rescue techniques are applied to increase the germination rate of true seed produced during breeding. More than 10,000 seeds obtained from plantain crosses are handled in the tissue culture laboratory at Onne each year. Technical assistance in developing tissue culture laboratories has been provided to national research institutions in Nigeria.

The usefulness of several modem biotechnologies currently are being investigated in collaboration with several laboratories. Work on the genetic stability of plants regenerated from cell suspensions and from cryopreserved 
cultures is underway with the Catholic Univ. of Leuven (Belgium). New molecular genetic techniques, i.e., using molecular markers (RFLPs, VNTRs, RAPDs) for phylogenetic studies, constructing a linkage map, breeding through marker-assisted selection, and mapping sigatoka resistance loci, are being investigated with R. Jarret of the Agricultural Research Service, U.S. Dept. of Agriculture, at Griffin, Ga.

Ecosystem analysis of sigatoka diseases in Africa. Despite its economic importance, little is known about the epidemiology of black sigatoka disease and about host plant $\times$ pathogen interactions. Detailed ecosystem analysis was begun at Onne in 1991 to provide abetter understanding of black sigatoka, particularly in the humid forest zone of sub-Saharan Africa. This work complements the breeding activity by providing baseline data on host plant $\mathrm{x}$ pathogen interaction and epidemiology that are required for developing durable host-plant resistance. This diagnostic analysis will also provide the framework to formulate and assess appropriate interventions in an integrated pest management strategy.

Diagnostic survey of banana pests in the highland banana system of East Africa. In Uganda, weevil and nematode attack in concert with land pressure and declining soil fertility have forced large areas to abandon banana production. More recently, black sigatoka has spread throughout the East African highlands, although its importance in mid-altitude systems remains unclear. IITA currently is conducting diagnostic surveys of banana systems in Uganda to determine the distribution, incidence, and importance of banana weevils, nematodes, and pathogens, and how these are affected by ecological factors and farming systems. Controlled experiments will be conducted to elucidate the interactions among banana pests, diseases, and other plant stresses, and to partition their influence on yield loss.
From these system analyses and ecological studies, ecologically sound control strategies are envisaged to develop. Work has begun in Uganda; parallel surveys are planned for the plantain systems in West Africa.

Postharvest research. Postharvest quality attributes related to fruit palatability and durability will strongly influence the adoption of improved cultivars. The project undertakes the appraisal of consumer preferences for and postharvest properties of new cultivars to ensure their acceptability and successful introduction. Research focuses on consumer response to new, black-sigatoka-resistant hybrids by investigating fruit palatability (flavor, texture, response to cooking procedures) and durability (shelf life, ripening, handling, and storage).

\section{Outlook for the future}

The most tangible achievement of plantain and banana research at IITA so far has been the development of black-sigatoka-resistant hybrids [see related article by Vuylsteke et al. (1993) on p. 957 of this issue]. Through a combination of conventional and new approaches, including interspecific hybridization, ploidy manipulation, in vitro culture, host plant $\times$ pathogen interaction studies, and field testing and selection, we have managed to breed resistant germplasm in just 5 years. The ultimate impact of this work will depend on how acceptable the new breeding materials are to national researchers and farmers, and on their success in making these an integral part of plantain and banana production systems.

\section{Literature Cited}

De Langhe, E. 1969. Bananas (Musa spp.), p. 5378. In: F.P. Ferwarda and F. Wit (eds.). Outlines of perennial crop breeding in the tropics. Misc. Papers 4, Agricultural Univ., Wageningen, The Netherlands.
Ortiz, R. and D. Vuylsteke. 1992. Inheritance of black sigatoka resistance and fruit parthenocarpy in triploid AAB plantain. Agron. Abstr. p. 109.

Simmonds, N.W. 1966. Bananas. 2nd ed. Longman, London and New York.

Swennen, R. 1990. Plantain cultivation under West African conditions. A reference manual. IITA, Ibadan, Nigeria.

Swennen, R. and D. Vuylsteke. 1991. Bananas in Africa Diversity, uses and prospects for improvement, p. 15 1-160. In: N.Q. Ng, P. Perrino, F. Attere, and H. Zedan (eds.). Crop genetic resources of Africa. vol. 2. Proc. Intl. Conf. IITA, Ibadan, Nigeria, Oct. 1988. Trinity Press, United Kingdom.

Swennen, R. and D. Vuylsteke. 1993. Breeding black sigatoka resistant plantains with a wild banana. Trop. Agr. (Trinidad) 70:74-77.

Vuylsteke, D. 1989. Shoot-tip culture for the propagation, conservation and exchange of Muss germplasm. Practical manuals for handling crop gennplasm in vitro 2. Intl. Board for Plant Genetic Resources, Rome.

Vuylsteke, D., J. Schoofs, R. Swennen, G. Adejare, M. Ayodele, and E. De Langhe. 1990. Shoot-tip culture and third-country quarantine to facilitate the introduction of new Muss gerrnplasm into West Africa. Plant Genetic Resources Nwsl. 81/ 82:5-11. Food and Agricultural Organization/ Intl. Board for Plant Genetic Resources, Rome.

Vuylsteke, D., R. Swennen, and E. De Langhe. 1991. Somaclonal variation in plantains (Muss spp. AAB group) derived from shoot-tip culture. Fruits 46:429-439.

Vuylsteke, D., R. Swennen, and R. Ortiz. 1993. Registration of 14 improved tropical Musa plantain hybrids with black sigatoka resistance. HortScience 28:957-959.

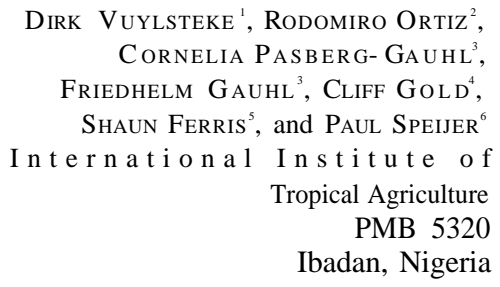

